\title{
Simultaneous "Bucket-Handle" Tear of Both Menisci on the Same Knee
}

M. Ouali idrissi ${ }^{1}$, Jaafari $\mathrm{F}^{1 *}$, Zouine $\mathrm{Y}^{1}$, Boutakiout $\mathrm{B}^{1}$, Cherif idrissi guennouni $\mathrm{N}^{1}$

${ }^{1}$ Radiology Department, ARRAZI Hospital, CHU Mohammed VI, Cadi Ayad University, Marrakech, Maroc

DOI: $10.36347 /$ sjmcr.2021.v09i03.013

| Received: 27.02.2021 | Accepted: 11.03.2021 | Published: 15.03.2021

*Corresponding author: Fadwa Jaafari

\section{Abstract}

About $10 \%$ of meniscal tears are bucket-handle tears and more frequently affect the medial meniscus three times more than the external meniscus. It turns out that the simultaneous tear in à bucket handle at the same knee is a rare phenomenon. In this article we report a case of a 25 -year-old man with a simultaneous bucket-handle tear in the same knee discovered on magnetic resonance imaging. Magnetic resonance imaging provides an accurate diagnosis of this type of injury.

Key words: Bucket-handle tear, MRI, Knee, Imaging.

Copyright $\odot 2021$ The Author(s): This is an open-access article distributed under the terms of the Creative Commons Attribution 4.0 International License (CC BY-NC 4.0) which permits unrestricted use, distribution, and reproduction in any medium for non-commercial use provided the original author and source are credited.

\section{INTRODUCTION}

MRI is the gold standard for evaluating meniscal lesions. It is of considerable sensitivity and specificity for revealing fissures, complications and associated lesions. A distinction is made between micro-traumatic fissures occurring on a degenerative meniscus and those traumatic in a healthy meniscus in young people, which are the most frequent (68 to $75 \%$ ) $[1,2]$.

The application of excessive mechanical stress to a healthy meniscus results in a traumatic injury [3]. Indirect valgus trauma with external rotation of the tibia on a knee flexed at $20^{\circ}$, or hyper-flexion followed by sudden lifting usually results in a fissure.

Broken meniscales in a bucket loop complicate the evolution of about $10 \%$ of vertical cracks with longitudinal extension $[4,5]$.

MRI has a sensitivity of $70 \%$ depending on the diagnostic criteria used. The most constant sign is to visualize directly the migrated fragment in the intercondylar space; the most pathognomonic sign being the "posterior double cruciate ligament (PCL)" is present in case of involvement of the medial meniscus without involvement of the anterior cruciate ligament, the dislocated fragement is then seen as an arciform band in hyposignal parallel to the posterior cruciate ligament thus giving the appearance of double LCP. A thickened anterior horn> $6 \mathrm{~mm}$ may also reflect a bucket handle lesion and the dislocated meniscal fragment is attached to the healthy anterior horn.

There are other signs that can be seen on MRI such as the tilted or inverted meniscus sign or the lack of visualization of the bow tie sign on coronal or axial millimeter views.

Coronal transverse and axial views better detect peripheral displacement of the meniscal fragment in the femoral-meniscal or femoral-tibial receptacle [4].

Although the bucket handle lesion is frequent in a compartment more precisely the medial one, involvement of both menisci of the same knee is rare, few cases being described in the literature [5-10].

\section{Clinical Case}

A 25-year-old patient with no particular medical history, an amateur football player, an accident victim in a football game. The patient had been seen in the ED and treated as sprained, with radiographs of the knee showing no sign of fracture. He received symptomatic treatment with rest and immobilization of the knee. Faced with no improvement, the patient reports feelings of knee clinging with cracking and fleeting sensation of instability as well as blocking. The physical examination showed + lachmann, + anterior drawer, central pivot, ++ mcmurray, + appley. 
The MRI showed a doublé delta monkey bilaterally next to the anterior meniscus horn ( Figure 1) as well as the sign of double posterior cruciate ligament, in relation to the central fragment of medial meniscus (Figure 2). On the coronal sequences, Four hyposignal structures were identified in the inter-condylian region, in connection with central fragments of medial and lateral meniscus and the posterior and anterior cruciate ligament (quadruple cruciate sign) (figure2). A torn anterior cruciate ligament (Figure 1).
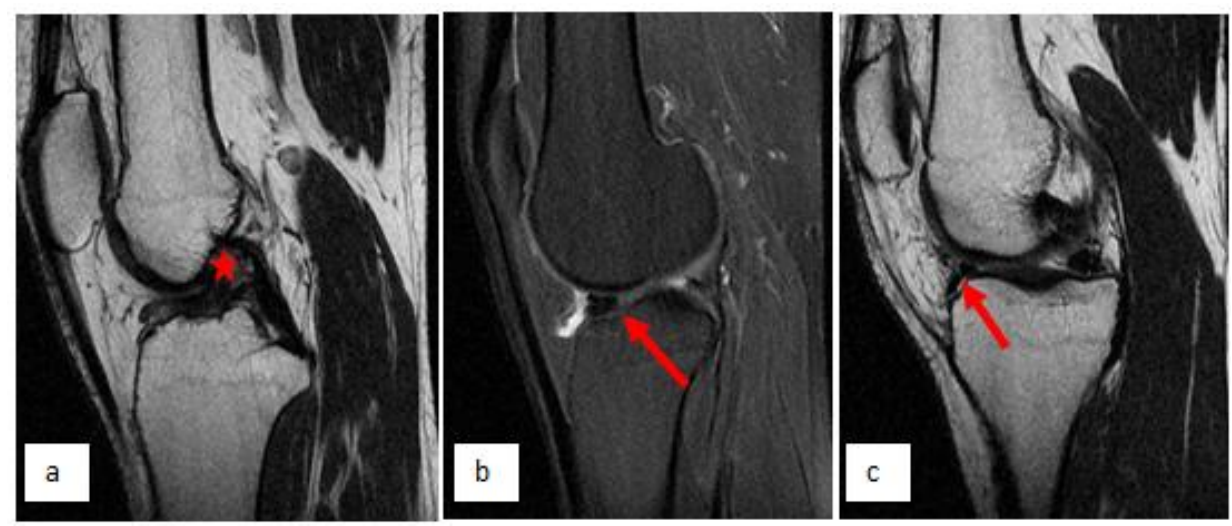

Fig-1, a: T2-weighted sagittal MRI. Star, torn anterior cruciate ligament. b- sagittal images weighted on protons. ; Arrows, the sign of the double delta, internal meniscus. c- T2-weighted sagittal MRI. ; Arrows, Double delta sign, external meniscus
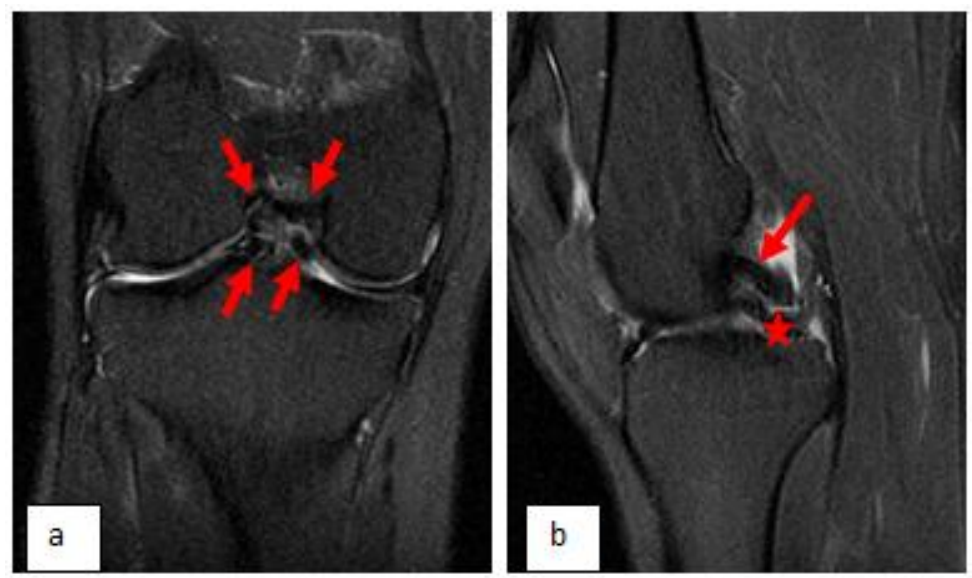

Fig-2, a-coronal images weighted on protons. Arrows, quadruple crucial sign. b- Sagittal images weighted on protons. The sign of the double posterior cruciate ligament; arrow, posterior cruciate ligament, star, meniscus dislocated

\section{DISCUSSION}

Meniscal "bucket handle" tears represent $10 \%$ of meniscal lesions and are found in young patients after trauma. They can occur suddenly if they are associated with an anterior cruciate ligament rupture, as reported in this article or following an istability of the chronic lesions. Physical examination usually finds joint blockage although it is absent. Sometimes in case of involvement of the lateral meniscus [2].

The specific signs in MRI are: 1 on the sagittal plane, the sign of the posterior double cruciate ligament, which is due to the interposition of the central fragment of the medial meniscus, in parallel and under the posterior cruciate ligament; 2, on the sagittal or coronary planes, the sign of the double meniscus / double triangle (double delta) which is the summation of the anterior or posterior horns and the adjacent inverted meniscal fragment; 3 Coronally, the meniscal fragment is identified at the level of the intercondylar notch [6,7]. In this study, we were able to see the double delta next to the anterior horn of both menisci, the sign of the posterior double cruciate ligament and the presence of meniscus fragments in the intercondylar region.

Brammer and Collars published the first case similar to ours and described the discovery as a "Jack and Jill injury" [8]. Bugnone et al. As well as Tecklenburg et al. Described a sign of the anterior quadruple cruciate ligament which reflects the presence of the anterior cruciate ligament, posterior cruciate ligament, and fragments of medial and lateral meniscus located at the level of the intercondylar notch on MRI in a 22-year-old patient after a motorcycle accident and in a professional athlete (skier) [6,9]. In our study, we were able to find this sign. Goms et les colliers reported à similar case to our study except that the ACL rupture was chronic [10]. 
M. Ouali idrissi et al., Sch J Med Case Rep, Mar, 2021; 9(3): 243-245

The ideal solution is a meniscal repair instead of a meniscectomy because of the important role of the meniscus in the transmission of the load through the knee joint thus on will have better functional results and avoid the risk of osteoarthritis $[11,12]$.

The risk of early osteoarthritis is high in the event of concervative treatment failure. Arthroscopic meniscectomy is only indicated if the dislocated bucket handle fracture is irreparable, irreducible, or difficult to repair.

Our patient had undergone a partial meniscectomy for both menisci. Shelbourne et al reported favorable but not the best results after partial meniscectomy of medial bucket-loop meniscus tears in knees without anterior cruciate ligament involvement after twelve years of long-term digital radiographic follow-up assessing the narrowing, of the medial joint space [13].

\section{CONCLUSION}

The simultaneous tear of the meniscus on the same knee in a "bucket handle" is a rare phenomenon. MRI is the gold standard in terms of diagnosis of this entity with high sensitivity and specificity equal to $90 \%$ [14].

\section{REFERENCES}

1. Resnick D, Kransdorf MJ. Internal derangements of joints, In: Resnick D, Kransdorf MJ, Bone and joint imaging. 3rd ed. Philadelphia: Elsevier Saunders. 2005: 945-74.

2. Cetik O, Cirpar M, Eksioglu F, Uslu M. Simultaneous bucket handle tear of both medial and lateral menisci of a knee with chronic anterior cruciate ligament deficiency. Knee Surg Sports Traumatol Arthrosc. 2006; 14:356-9.

3. Trillat A. Lésions traumatiques du ménisque interne du genou, classification anatomique et diagnostic clinique Rev Chir Orthop. 1962; 48: 551-560

4. Van de Berg BC, Malghem J, Poilvache P, Maldague B, Lecouvet FE. Meniscal tears with fragments displaced in notch and recesses of knee:
MR imaging with arthroscopic comparison Radiology. 2005; 234: 842-850 [crossref]

5. Cargill AO, Jackson JP. Bucket-handle tear of the medial meniscus J Bone Joint Surg. 1976; 58A: 248-251

6. Bugnone AN, Ramnath RR, Davis SB, Sedaros R. The quadruple cruciate sign of simultaneous bicompartmental medial and lateral bucket handle meniscal tears. Skeletal Radiol. 2005; 34:740-4.

7. Dorsay TA, Helms CA. Bucket handle meniscal tears of the knee: sensitivity and specifity of MRI signs. Skeletal Radiol. 2003; 32:266-72.

8. Brammer H, Sover E, Erickson S, Stone J. Simultaneous identification of medial and lateral bucket handle tears: the Jack and Jill lesion. AJR Am J Roentgenol. 1999; 173:860-1.

9. Tecklenburg K, Schoepf D, Hoser C, Fink C. Anterior cruciate ligament injury with simultaneous locked bucket handle tears of both medial and lateral meniscus in a 19 year old female professional ski racer: a case report. Knee Surg Sports Traumatol Arthrosc. 2007; 15:1125-9.

10. Gomes AF, Paganella VC, Zapparoli M, Zanoni EK, Lucaski FF and Aguiar R. Rotura em "alça de balde" simultânea dos meniscos no mesmo joelho. Acta Ortopédica Brasileira. 2009; 17(4), 247-249.

11. Shelbourne KD, Dersam MD. Comparison of partial meniscectomy versus meniscus repair for bucket-handle lateral meniscus tears in anterior cruciate ligament reconstructed knees. Arthroscopy. 2004; 20: 581-585.

12. Baratz ME, Fu FH, Mengato R. Meniscal tears: the effect of meniscectomy and of repair on intraarticular contact areas and stress in the human knee: à preliminary report. The American journal of sport medicine. $1986 \mathrm{Jul} ; 14(4): 270-5$.

13. Shelbourne KD, Dickens JF. Digital Radiographic Evaluation of Medial Joint Space Narrowing after Partial Meniscectomy of Bucket-Handle Medial Meniscus Tears in Anterior Cruciate LigamentIntact Knees. The American journal of sport medicine. 2006 Oct;34(10):1648-55.

14. Magee TH, Hinson GW. MRI of meniscal buckethandle tears. Skeletal radiology. 1998 Sep;27(9):495-9. 